Research Article

\title{
Investigation of Pore Structure and Water Imbibition Behavior of Weakly Cemented Silty Mudstone
}

\author{
Shuai Wang $\mathbb{D}^{1},{ }^{1}$ Lijun Han $\mathbb{D}^{1},{ }^{1}$ Qingbin Meng, ${ }^{1}$ Yuhao Jin $\mathbb{D}^{1},{ }^{1}$ and Weisheng Zhao ${ }^{2}$ \\ ${ }^{1}$ State Key Laboratory for Geomechanics and Deep Underground Engineering, China University of Mining and Technology, \\ Xuzhou, Jiangsu 221116, China \\ ${ }^{2}$ Institute of Mining Engineering, Guizhou Institute of Technology, Guiyang 550003, China \\ Correspondence should be addressed to Lijun Han; hanlj@cumt.edu.cn
}

Received 11 April 2019; Revised 15 May 2019; Accepted 27 May 2019; Published 18 June 2019

Academic Editor: José Aguiar

Copyright (C) 2019 Shuai Wang et al. This is an open access article distributed under the Creative Commons Attribution License, which permits unrestricted use, distribution, and reproduction in any medium, provided the original work is properly cited.

\begin{abstract}
Water-rock interaction of weakly cemented mudstone is intense due to its complex pore structure and mineral compositions. As primary channels for water imbibition, pore structures determine water migration. In this paper, pore properties of weakly cemented mudstone are measured by scanning electron microscopy (SEM), nitrogen adsorption/desorption (NAD), and mercury intrusion porosimetry (MIP), respectively. Water imbibition tests under free and lateral restraints are performed on selfdeveloped water absorption instruments. The results show that skeleton aggregates, pore zone, and fissure zone constitute the basic structure of the rock, together with pore scales in nanoscale, submicron-scale, and micron-scale, respectively. The porosities of each zone are inferred with the values of $13.5 \%, 7.3 \%$, and $2.3 \%$ by comparison of different methods. The main pore type is mesopore. Based on water imbibition tests, water rises along the large fissure and pore zones initially. Pores in the skeleton aggregates absorb water from pore and fissure zones subsequently. However, water imbibition is limited under lateral restraints. Owing to lateral restraints, the ascending height and rate of the sample with lateral restraints are lower than those of the sample with free confinements. The results suggest that lateral restraints can restrain water migration and water-rock interaction for weakly cemented mudstones, and measures can be taken to control swelling deformation by strengthening lateral restraints.
\end{abstract}

\section{Introduction}

Weakly cemented strata formed in the period of Late Cretaceous are prevalent in coalfields in eastern Inner Mongolia, China. According to geological investigation reports of Xiyi Coal Mine in Wujianfang, the strata are characterized by shallow burial, late diagenesis, and clay bearing, which are adverse for coal mining. This sort of rock is susceptible to water, followed by argillization and disintegration after contact with water. The rock structure determines the intension of water imbibition. Variation in water content exerts great influences on the stability of weakly cemented rock mass. Tang studied the relationships between the elastic modulus, uniaxial compressive strength, and water content by considering the water soaking duration, water distribution, and loading-saturation sequence of the black sandstone [1]. The evaluation of rock mass is critical before engineering constructions. Pore structure and lithology are key factors for identifying mechanical properties. Robertson found that decreasing porosity increases the deformability of clay after submerging in water [2].

Since the last century, many comprehensive studies have been carried out on the petrophysical characteristics of underground radioactive waste storage and oil/gas reservoirs, which are characterized by low permeability, strong cementation, lower moisture content, and well diagenesis [3-5]. Zhang et al. and Guo et al. studied the water absorption of weakly cemented sandstone by a self-designed instrument of water imbibition and concluded that water absorption presents exponential relationship over time $[6,7]$. Yilmaz, Yilmaz el al., and Cao et al. studied the strength and microstructural properties of cemented tailings 
backfill [8-10]. However, properties of weakly cemented mudstone characterized by high porosity, strong water absorption, low strength, and bad slake durability have rarely been studied.

Scanning electron microscopy (SEM) and micro-X-ray computed tomography $(\mu$-CT) are common direct measurement methods of pores at scales of microns and submicrons [11]. Transmission electron microscopy (TEM) is a promising method for studying pore structures of finegrained rocks, which contain smaller pores in nanoscale [12]. Other indirect testing methods such as mercury intrusion porosimetry (MIP), nitrogen adsorption/desorption (NAD), and $\mathrm{CO}_{2}$ adsorption/desorption (CAD) are also widely adopted together with direct methods. Li et al. carried out tests of MIP, NAD, and nuclear magnetic resonance (NMR) together on marine and continental shale to uncover the pore structures [13]. Due to distinctions in testing principles, the applicable scale of each method is limited. Gaucher et al. summarized the suitable extent of different testing methods: SEM for macropores, NAD for mesopores, CAD for micropores, and MIP for both mesopores and macropores [14].

SEM is a common method to study rock structure [15]. The principle is that the electron beam deflects and concentrates when passing through the electromagnetic field, bombarding the surface of testing samples subsequently, and then the electronic signal can be received for imaging finally. Mineral particle sizes and contact modes, pore sizes and shape, and pore connectivity can be recognized directly by SEM [16]. However, this method only reflects local features of samples due to limited view under the high magnification. Saraji and Piri acquired the pore size distribution (PSD) by comparing SEM images of different magnifications and classified the pore systems into organic, intraparticle, and interparticle pores [17].

MIP is based on the fact that mercury cannot infiltrate into pores unless extra pressure is loaded to overcome surface resistivity. Immersion pressure and pore size are in the one-to-one correspondence. PSD can be inferred from the capillary pressure curve. Allen et al. obtained porosity and PSD of sedimentary rock by MIP [18].

Intraparticle pore, interparticle pore, and corroded pore are formed during the diagenesis, dispersing in the rock randomly [19]. According to the contribution to fluid percolation, the pores are divided into 3 categories, as shown in Table 1 [20]. Pore classifications are listed in Table 2 based on Hodot [21] and IUPAC [22].

Rock is a porous media material. Moisture migrates along connected pores and fissures under capillary force once exposed to water $[23,24]$. Lerouge et al. studied the effect of degrees of hydrophobicity and pore size levels (monoporous and biporous materials) on water absorption for organic materials [25]. Initial water content also influences the intensity of water absorption. The less the water content is, the more the water absorption content will be [26]. Rock structures determine the water migration process. Ghanbari and Dehghanpour found that the fabric of shale influences the behavior of water imbibition [27]. Huang et al. carried out capillary test on vertically aligned carbon nanotube (CNT) arrays to acquire the wetting characteristics in different heights by using a visualization system [28]. Yang et al. quantified the impact of the volumetric response (swelling and shrinkage) of gas shales on the water uptake during imbibition and desiccation processes [29].

Pore structures of high-rank coal, shale, and sandstone in reservoirs have been studied comprehensively in the existing literature, and relationships between pore structure and water imbibition have been established [30-32]. However, the bonding force between above structures is relatively strong, and changes of pore structures are not obvious during water imbibition. The weakly cemented silty mudstone, which was formed in the Late Cretaceous, is subject to significant damages during water intrusion for its complicated pore structures. Therefore, it is profoundly significant to study the pore structure of weakly cemented rock and analyze water migration law during water absorption, which is conducive to make the supporting scheme before the engineering.

In this paper, mineral components for the weakly cemented mudstone are firstly analyzed by XRD and pore properties are measured by SEM, NAD, and MIP, respectively. In order to illustrate the water migration process, the water absorption instrument with special functions is developed. This equipment can monitor the water imbibition process in real time, and the water temperature can also be set according to the test requirements. Two test schemes for water absorption, under free and lateral restraints, are carried out. Therefore, the influence of the pore structure on water absorption can be analyzed.

\section{Materials and Methods}

2.1. Materials. The studied strata, which were formed in the period of Upper Cretaceous, present weak cementation and fragile physical and mechanical properties, characterized by late diagenesis, strong water sensitivity, and shallow burial in the eastern Inner Mongolia, China. When the rock is exposed to water, expansion, argillization, and disintegration occur.

The weakly cemented samples in this paper are drilled from the floor of No. 3-3 coal seam, with a burial depth from $102.57 \mathrm{~m}$ to $702.39 \mathrm{~m}$, averaging in $300 \mathrm{~m}$, possessed by Xiyi Coal Mine, Wujianfang, subordinated by China Resources Power Holdings Company Limited. According to X-ray diffraction analysis (see Figure 1), the lithological floor is silty mudstone. The main components include quartz, feldspar, and clay minerals with contents of $48 \%, 12 \%$, and $36 \%$, respectively. The amount of secondary minerals, such as calcite and mica, is rare, only taking up 4\%. The primary swelling mineral is illite/smectite formation, accounting for $40 \%$ of all clay minerals.

\subsection{Measurement of Pore Structure}

2.2.1. SEM. The distribution of pore structures and minerals has a high anisotropy for weakly cemented mudstones. It is important to determine reasonable magnification times and viewpoints to obtain more microstructures by using SEM. 
TABle 1: Pore classification based on the contribution to fluid percolation.

\begin{tabular}{lccc}
\hline Type & Supercapillary opening & Capillary opening & Microcapillary opening \\
\hline Size $(\mu \mathrm{m})$ & $>500$ in diameter of pores & From 500 to 0.2 in diameter of pores & Less than 0.2 in diameter of pores \\
Fluid state & $>250 \mu \mathrm{m}$ in width of fissures & From $250 \mu \mathrm{m}$ to $0.1 \mu \mathrm{m}$ in width of fissures & Less than 0.1 in width of fissures \\
\hline
\end{tabular}

TABLe 2: Pore size classification.

\begin{tabular}{lcccc}
\hline Type & Micropores $(\mathrm{nm})$ & Submesopore $(\mathrm{nm})$ & Mesopores $(\mathrm{nm})$ & Macropores $(\mathrm{nm})$ \\
\hline Hodot & $<10$, adsorption & $10 \sim 100$, condensation/diffusion & $100 \sim 1000$, stable laminar flow & $>1000$, unstable laminar flow \\
IUPAC & $<2$ & $2 \sim 50$ & $>50$
\end{tabular}

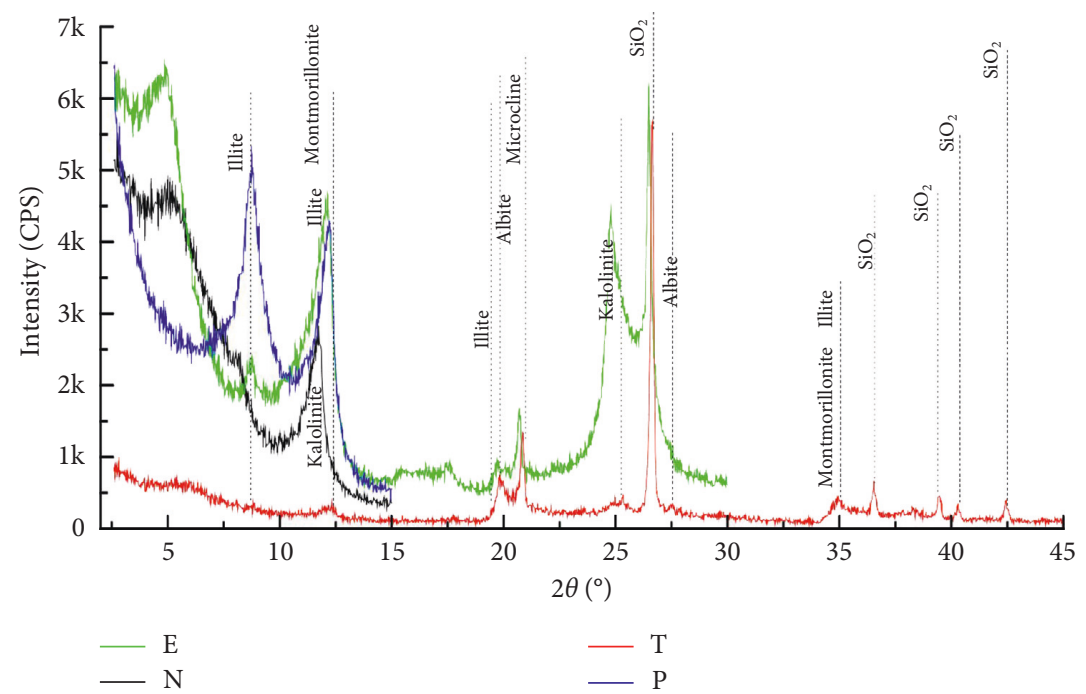

FIGURE 1: XRD spectrum of weakly cemented mudstone.

Firstly, images were magnified to $2000 \times$ to determine the initial viewpoint where most structures can be found; secondly, the next interesting viewpoint with more pores is selected at a magnification of 5000×; finally, at higher magnification of $10,000 \times$, pore size, contact modes between grains, and connectivity of pores were observed clearly. Prior to the SEM study, low-power manual cutting machine was used to make a cubic sample of $1 \mathrm{~cm} \times 1 \mathrm{~cm} \times 1 \mathrm{~cm}$ and freeze-dried method was adopted to remove pore water, which can avoid damages to the pore structure at most. The study was performed on FEI Quanta TM 250 instrument with a working current at $20.00 \mathrm{kV}$ in the Advanced Analysis and Computation Center, China University of Mining and Technology.

2.2.2. NAD. NAD tests are carried out on the Automatic Specific Surface Area and Pore Analyzer of TriStar II 3020 in the Key Lab of Coalbed Methane Resources and Reservoir Formation Process, China University of Mining and Technology. The parameters of the instrument are set with a constant temperature of $77.35 \mathrm{~K}$, relative pressure ranging between 0 and 1, and $\mathrm{N}_{2}$ concentration above $99.99 \%$.

Two sets of samples noted by CR-A and CR-B with a weight of $3.46 \mathrm{~g}$ and $2.75 \mathrm{~g}$ were prepared, respectively. To obtain the particles required for the NAD test with granularity from 60 to 80 in mesh, samples were broken by a ball mill and separated by a mesh screen, corresponding to equivalent diameter from $180 \mu \mathrm{m}$ to $250 \mu \mathrm{m}$. Moisture and gas have significant effects on NAD methods. Prior to the test, freeze-drying and outgassing under vacuum were carried out to remove water and gas.

2.2.3. MIP. Mercury, as the nonwetting phase for rock materials, cannot infiltrate into pores without external pressure. Initially, the mercury flows into large pores at lower pressure and subsequently fills small pores under the higher pressure. Washburn found that the applied pressure is inversely proportional to the size of intruded pores according to the capillary pressure curve $[33,34]$. Assuming that pores are cylindrical, Washburn equation (1) is derived, which represents the relationship between intrusive pressure and pore sizes as follows:

$$
P_{\mathrm{m}}=\frac{-2 \sigma \cos \theta}{r}
$$

where $P_{\mathrm{m}}$ is the intrusive pressure, $\mathrm{Pa} ; \sigma$ is the mercury surface tension, $485.00 \mathrm{~N} / \mathrm{cm}$; $\theta$ is the contact angle, $140^{\circ}$ for mercury; and $r$ is the equivalent pore radius, $\mathrm{cm}$. 
The MIP test was conducted on the 9505 AutoPore IV Mercury Porosimeter in Beijing, which can identify pore size ranging from $0.003 \mu \mathrm{m}$ to $1100 \mu \mathrm{m}$. Prior to the test, the sample was crushed into a size of $\sim 1 \mathrm{~cm}$. The sample preparation process was similar to that in Section 2.2.1. The process of dehydration and outgassing was done. The maximum intruded pressure was $200 \mathrm{MPa}$ in the test, indicating that the minimum pore size of $4 \mathrm{~nm}$ can be measured.

\subsection{Water Imbibition Tests}

2.3.1. Water Imbibition Instrument. In order to study the law of water migration, the water imbibition instrument with special functions is designed, which can conduct tests under different water contents, water temperatures, and lateral restraints. The process of water migration is recorded by the digital cameras (see Figure 2).

The instrument consists of the water sink (13), sample tubes (1), sample platforms (7), weighing system (7, 8, 9, 10, 25), monitoring system (23), water temperature control system $(11,12,24)$, and leveling system $(14,15)$. To monitor the water migration, sample tubes are made of highly transparent plexiglass, whose size can be customized in accordance with the sample size. The tube walls are taken as the role of lateral restraints. The weighing module records the weight in real time. The monitoring system can record the movement of the infiltration level. To prevent disintegrated grains from intruding into the sink, porous stones and filter papers are placed on the bottom of sample tubes from down to up successively.

In this study, the water imbibition content was not measured and immersion depth of samples is constant to $2 \mathrm{~mm}$. A simplified instrument including the digital photogrammetry system, thermostat water bath, sample tubes, and tube platform was made (see Figure 2(b)).

2.3.2. Sample Preparation. Pores and fissures are main channels for water imbibition. However, new voids may occur during sampling. To acquire original rock samples, the low-power grinding machine is used, which can avoid damages to the pore structure at most during sample preparation. Water imbibition for sedimentary rock is direction dependent, which is more intense along the strike of the beddings than other directions [35]. The bedding plane of cuboid samples is vertical in the test. According to principles mentioned above, two regularly cuboid samples are prepared from initial rock cores (see Figure 3). The surfaces of samples are smoothed with sandpapers carefully. Prior to tests, these samples are wrapped with a preservative film to prevent weathering.

2.3.3. Test Procedures. Two groups of tests are carried out under free and lateral restraints, respectively. The test process is detailed as follows:

(1) Select two cuboid samples with a similar surface morphology, named as $1 \#$ and $3 \#$, respectively. $1 \#$ is for water imbibition with lateral restraints while $3 \#$ is for water imbibition with free confinements. Prior to tests, sample size and weight are measured and surface morphology of the sample is recorded by the digital camera.

(2) Place samples in sample tubes. For group of 1\#, intervals between the sample and tube walls are stuffed up with organic glass plates to provide lateral restraints.

(3) Set the water temperature. Heat water up to $30^{\circ} \mathrm{C}$ and place sample tubes on the platform as soon as the objective temperature is achieved. Adjust the platform height to guarantee that the water level is $2 \mathrm{~mm}$ above the sample bottom.

(4) Take photos at intervals of $10 \mathrm{~s}, 30 \mathrm{~s}, 60 \mathrm{~s}, 5 \mathrm{~min}$, $10 \mathrm{~min}, 30 \mathrm{~min}, 1 \mathrm{~h}$, and $1 \mathrm{~h}$. Stop tests until there is no obvious variation of intruded line or the sample is saturated entirely.

(5) Take out the sample and weigh.

It should be noted that the friction between the cell walls and the specimen is negligible because of the cell walls' lower coefficient of friction. The axial swell for the specimen is free with the height increasing during water imbibition. However, the axial expansion is small compared with the sample height due to its weak expansion.

\section{Results}

\subsection{Pore Characteristics}

3.1.1. SEM. SEM images of different magnifications are presented in Figure 4. The image of $2000 \times$ magnifications verifies that skeleton aggregates, pore zone, and fissure zone constitute the basic structure of the rock. The contact between each zone is uneven. Macropores mainly exist in pore zones where the main pore type is intergranular pores with the diameter ranging from a few hundred nanometers to a few microns. The maximum width of the pore zone approximates $40 \mu \mathrm{m}$. Irregularly flaky illite particles are dispersed in pore zones by means of local filling with a size of $0.15 \sim 0.50 \mu \mathrm{m}$, presenting point contacts mainly according to the image of $10,000 \times$ magnifications. Multilayer particles of the illite/smectite formation are embedded in pore zones, shaped like honeycomb. The edges of some pores are covered with bright-colored mineral, such as calcite. Skeleton aggregates appear compact relatively. Fissure zones stretch along the contact between skeleton aggregates, and the crack is opened in micrometers. The crack tips and throats are also filled with soluble minerals of calcite.

3.1.2. MIP. Primary parameters of pores are obtained from the capillary pressure curve as shown in Table 3 . The capillary pressure curve and PSD are presented in Figures 5 and 6 , respectively. The hysteresis is prominent between mercury curves of injection and ejection, indicating that there are large amounts of ink-bottle pores. The PSD is concentrated in ranges from $10 \mathrm{~nm}$ to $20 \mathrm{~nm}$. According to the Hodot 


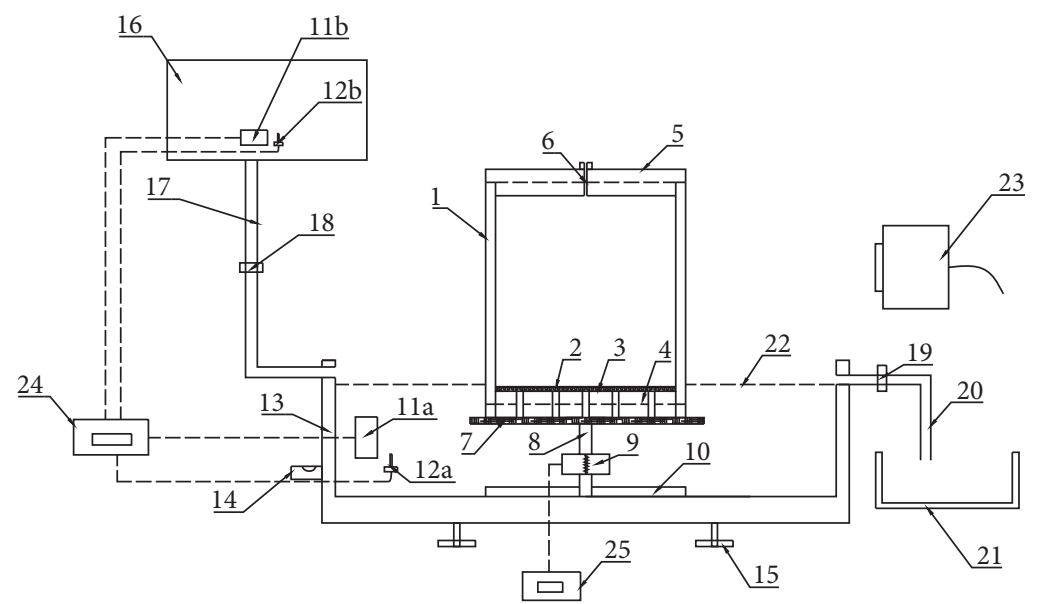

(1) Sample tube, (2) Filter paper, (3) Porous stone, (4) Base plate of tube,

(5) Cap of tube, (6) Pressure relief valve, $(7,8,9,10,25)$ Weighing system,

(13) Water sink, (14), (15) Leveling system, $(11,12,24)$ Water temperature control system, (23) Monitoring system.

\section{(a)}

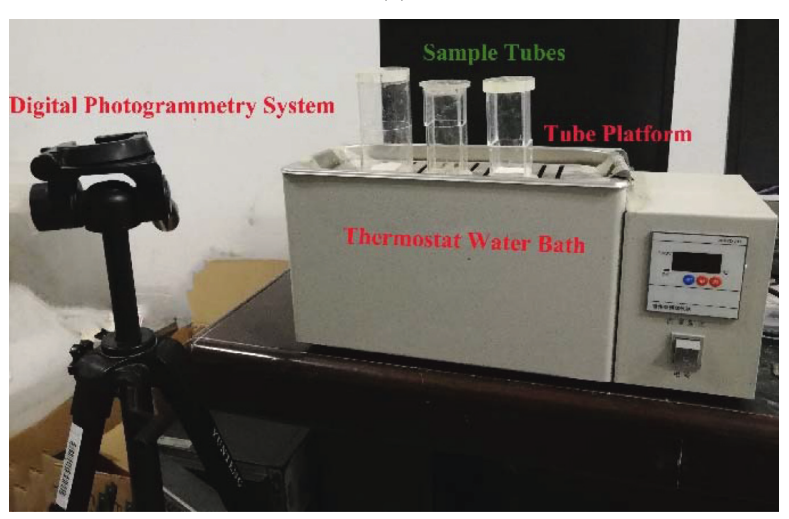

(b)

FIgURE 2: Diagram of the water imbibition instrument. (a) The design drawing; (b) pictures of the real product.

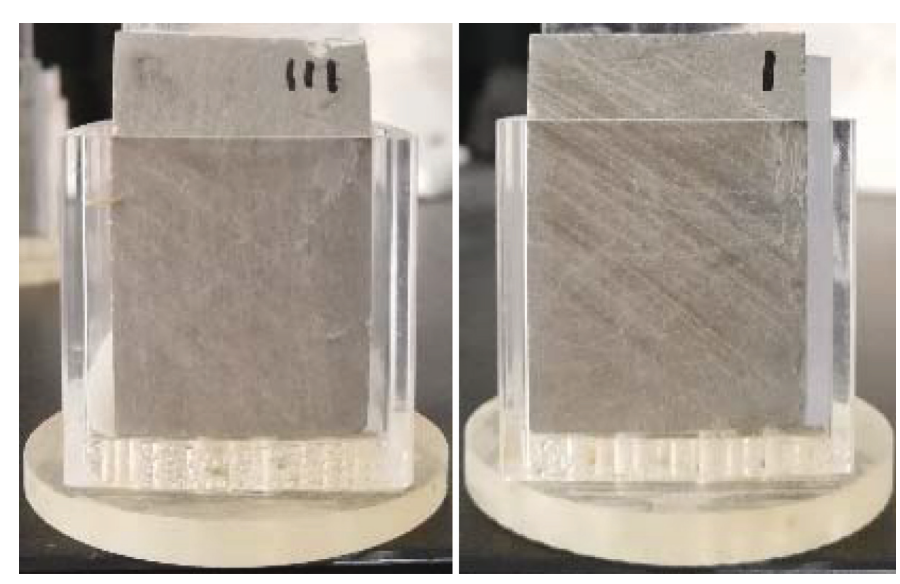

(a)

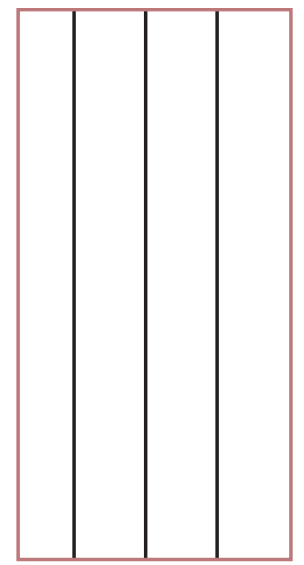

(b)

FIGURE 3: Sample preparation. (a) Samples in tubes for water imbibition; (b) joint direction of samples 3\# and 1\#. 


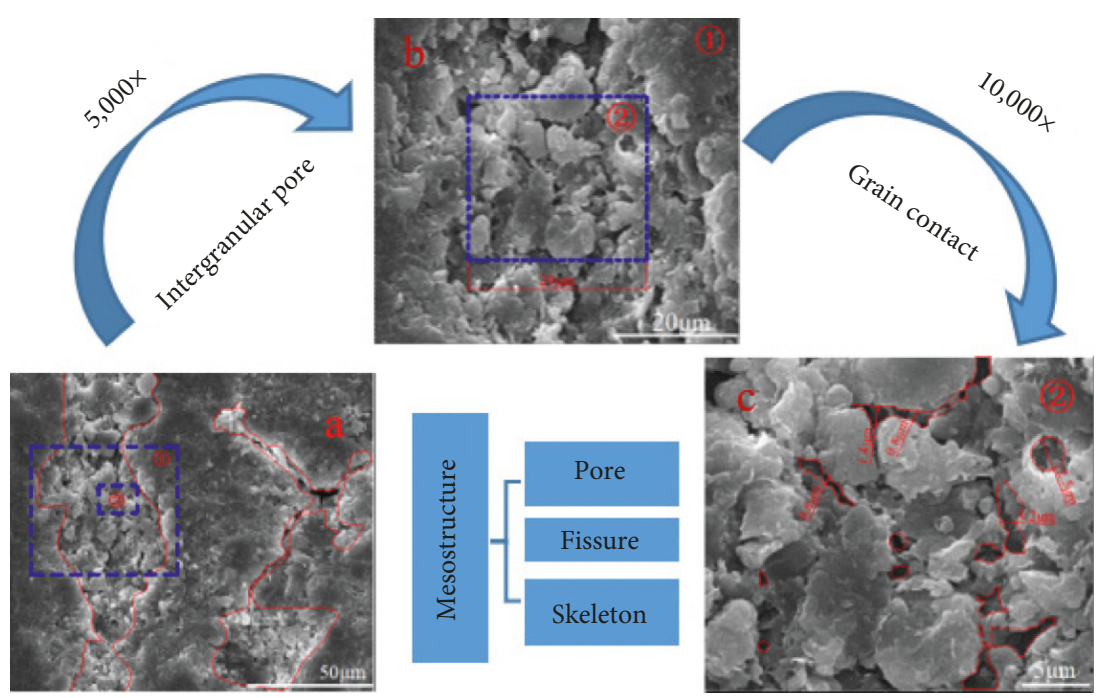

Figure 4: SEM images under different magnifications: (a) 2000×, (b) 5000×, and (c) 10,000×.

TABLE 3: Critical parameters of pores.

\begin{tabular}{lcc}
\hline Total porosity $(\%)$ & $\begin{array}{c}\text { Average pore } \\
\text { diameter }(\mathrm{nm})\end{array}$ & $\begin{array}{c}\text { Maximum pore } \\
\text { diameter }(\mathrm{nm})\end{array}$ \\
\hline 20.79 & 14 & 53 \\
\hline
\end{tabular}

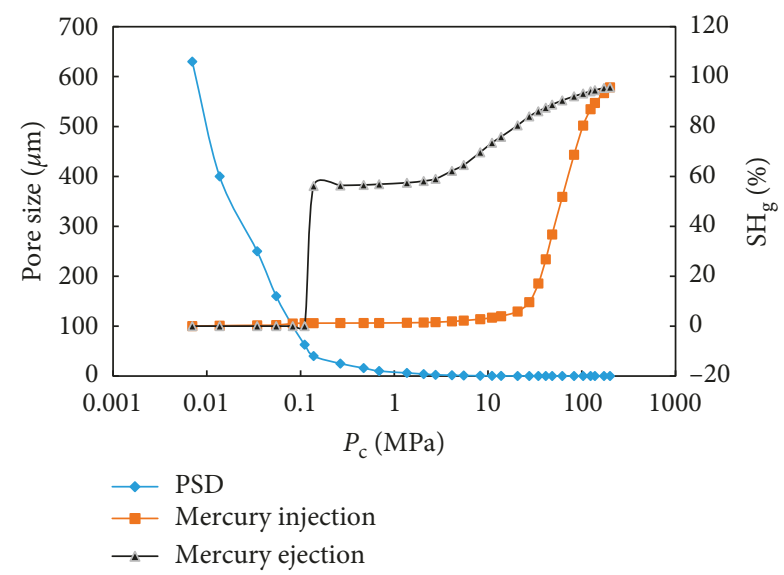

Figure 5: Capillary pressure curves. $P_{\mathrm{c}}$ represents intrusion pressure.

classification, the pore type belongs to transition pore $(10 \mathrm{~nm} \sim 100 \mathrm{~nm})$.

3.1.3. NAD. The primary parameters are listed in Table 4. Results of CR-A and CR-B samples are similar, indicating that test results are representative. Therefore, only CR-A results are analyzed in detail. Figure 7 shows the S-shaped relationship between the adsorbed/desorbed volume and the relative pressure $\left(P_{\mathrm{c}} / P_{0}, P_{0}\right.$ refers to saturation pressure.) for the CR-A sample. PSD and specific surface area (SSA) can be derived by data from isotherm desorption branch by using Barrett-Joyner-Halenda (BJH) model and BrunauerEmmett-Teller (BET) model, respectively [36]. Figure 8 presents the PSD based on $\mathrm{BJH}$.

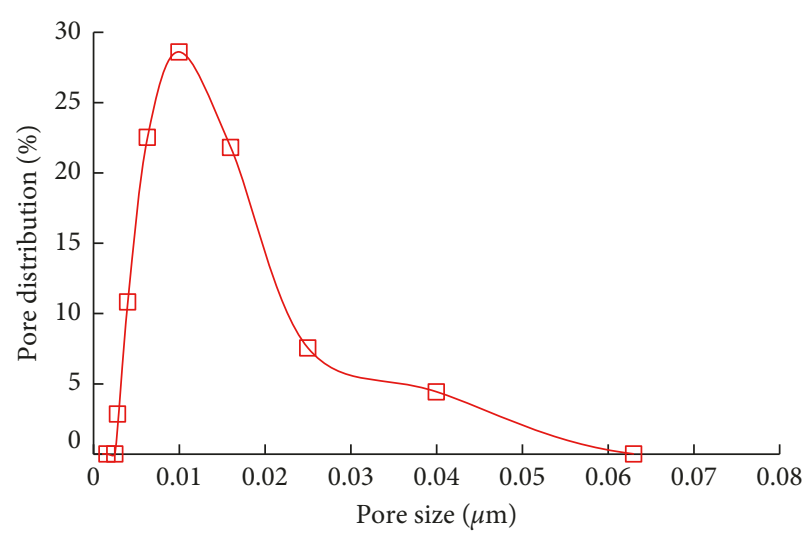

Figure 6: PSD curves.

The adsorption/desorption isotherm reflects pore characteristics of rock masses. According to IUPAC [37], the adsorption/desorption isotherm of the sample approximates the IV type, which means that the weakly cemented mudstone is a typical mesoporous material, showing both hysteresis and single-layer adsorption. The adsorption process is divided into three stages based on $\left(P_{c} / P_{0}\right)$ : low pressure, middle pressure, and high pressure, respectively.

(1) Low pressure (0.001 0.05): the binding capacity between solid phases and fluid phases is strong on the micropore surface due to the high specific surface energy. The adsorption occurs even under the low immersion pressure. In this stage, the gas adsorption type is monolayer adsorption, which primarily occurs in micropores, and the adsorption amount increases from 0.00 to $7.06 \mathrm{cc} / \mathrm{g}$.

(2) Middle pressure (0.05 0.50): the adsorption potential energy decreases rapidly once monolayer $\mathrm{N}_{2}$ covers over the pore surface. The continuous adsorption requires greater relative pressure. The adsorption amount increases linearly with the increasing relative pressure, but the adsorption rate is small, as shown in 
TABLE 4: NAD results.

\begin{tabular}{lcccccc}
\hline Sample type & Mass $(\mathrm{g})$ & Size $(\mathrm{mesh})$ & Total pore volume $(\mathrm{cc} / \mathrm{g})$ & Porosity $(\%)$ & Surface area $\left(\mathrm{m}^{2} / \mathrm{g}\right)$ & Average pore diameter $(\mathrm{nm})$ \\
\hline CR-A & 3.47 & $60-80$ & $6.73 e-02$ & 13.26 & 32.55 & 8.27 \\
CR-B & 2.75 & $60-80$ & $6.96 e-02$ & 13.71 & 32.95 & 8.44 \\
Average & 3.11 & $60-80$ & $6.85 e-02$ & 13.49 & 32.75 & 8.35 \\
\hline
\end{tabular}

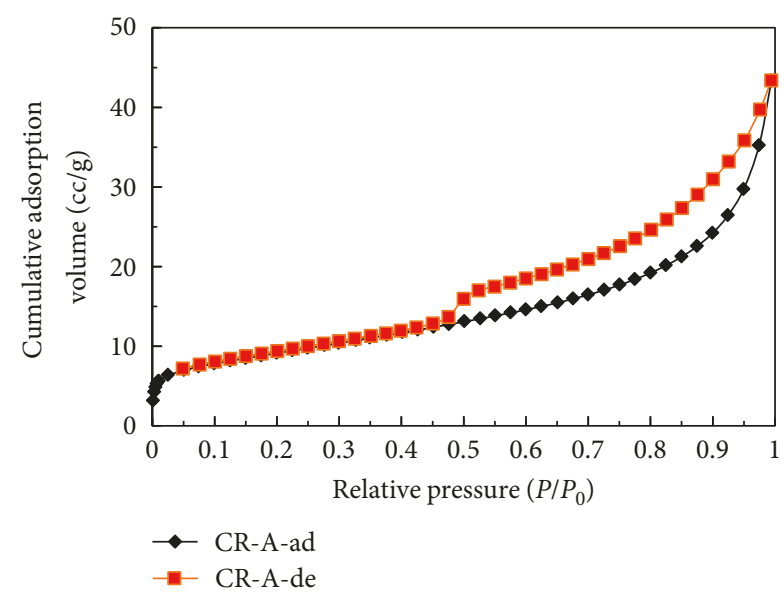

Figure 7: CR-A adsorption/desorption isotherm. $P$ represents the absolute pressure, $P_{0}$ represents the saturation pressure of the adsorbent, CR-A-ad represents the adsorption process, and CR-Ade represents the desorption process.

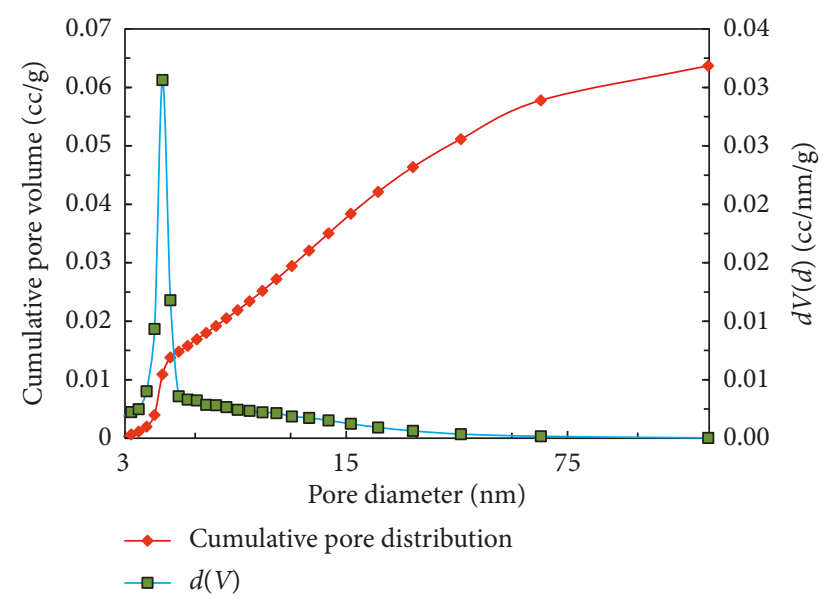

FIgUre 8: The curve of PSD.

Figure 5. In this stage, it is the multilayer adsorption, which occurs in medium pores mainly, and the adsorption amount increases from $7.06 \mathrm{cc} / \mathrm{g}$ to $13.17 \mathrm{cc} / \mathrm{g}$.

(3) High pressure (0.50 0.99): the adsorption amount increases from $13.17 \mathrm{cc} / \mathrm{g}$ to $43.00 \mathrm{cc} / \mathrm{g}$ at the end. The capillary condensation of $\mathrm{N}_{2}$ molecules occurs in bigger pores and fractures. The pores are filled up with condensed $\mathrm{N}_{2}$ molecules until saturation pressure is attained. The adsorption rate increases with the increasing pressure gradually.

According to the IUPAC hysteresis classification, the adsorption/desorption isotherm of weakly cemented mudstone approximates to $\mathrm{H}_{3}$ type. The minimum capillary condensation begins at a relative pressure of 0.5 . The pores are shaped in narrow slit, which is caused by lamellar particle accumulations. The variation in pore size leads to the slow drop of desorption curve in the branch due to the nonparallel between the plates.

According to the IUPAC classification, the main pore type is medium pore $(2 \mathrm{~nm}-50 \mathrm{~nm})$, and the cumulative pore volume is $5.45 \times 10^{-2} \mathrm{cc} / \mathrm{g}$, accounting for $85.60 \%$ of the total. The volume of bigger pores $(>50 \mathrm{~nm})$ is small, and the cumulative volume is $0.92 \times 10^{-2} \mathrm{cc} / \mathrm{g}$, only accounting for $14.40 \%$ of the total.

3.2. Moisture Migration Process. Water rises along connected pores under capillary forces when the sample is exposed to water. Figures 9 and 10 present the water imbibition process and variation of intruded height over time under free and lateral restraints, respectively. Figures 11 and 12 present the water imbibition height and variation rate at any time, respectively.

Spontaneous imbibition is conducted to $3 \#$ sample under the free restraints. We can see that the intruded line is uneven across the cross section in Figures 9 and 10, which is related to nonuniform expansion of minerals. The nonuniformity is caused by the inhomogeneous distribution of swelling clay minerals and pores. In the initial phase, moisture rises faster in laterals than that in the middle. Ten minutes later, the line tends to be uniform. Furthermore, the line turns to be uneven with the duration increasing. Besides, nonuniformity increases with time, followed by transverse cracks developing and openings enlarging. Water intrudes the whole sample 1000 minutes later. The deformation on the left is much larger than that on the right. During water migration, the intruded line experiences uneven, even, and uneven.

The water imbibition test under lateral restraints is performed on $1 \#$ sample. The water migration obviously differs from 3\# sample (see Figure 9). The intruded line is uniform across the cross section initially. Nine minutes later, the intrusion line tends to be uneven with the left rising up faster than the right. Subsequently, the rising rate of the right gradually increases and gets the same height as the left at 170 minutes. The rising height and rate in the middle are less than those in the laterals. The intruded line tends to be constant at 1360 minutes ultimately. The water is unable to intrude the whole height, indicating that the moving distance is limited under lateral restraints.

In the initial phase, the variation rate of intruded height is high for both samples and decreases over time (see Figure 12). However, the rising height and variation rate of $1 \#$ sample are lower than that of $3 \#$ due to lateral restraints. 

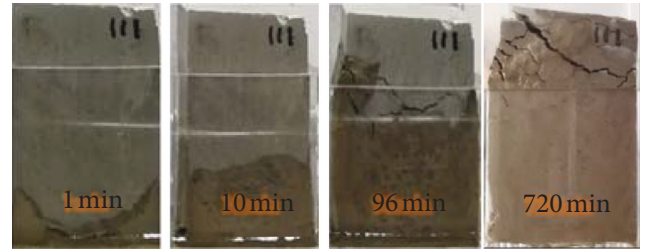

(a)
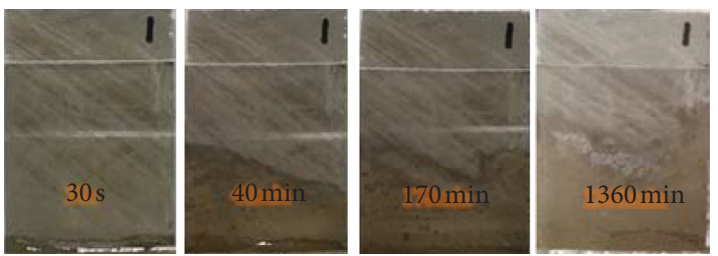

(b)

FIGURE 9: Images of spontaneous imbibition from the bottom. (a) 3\# sample is under free restraints. (b) 1\# sample is under lateral restraints.
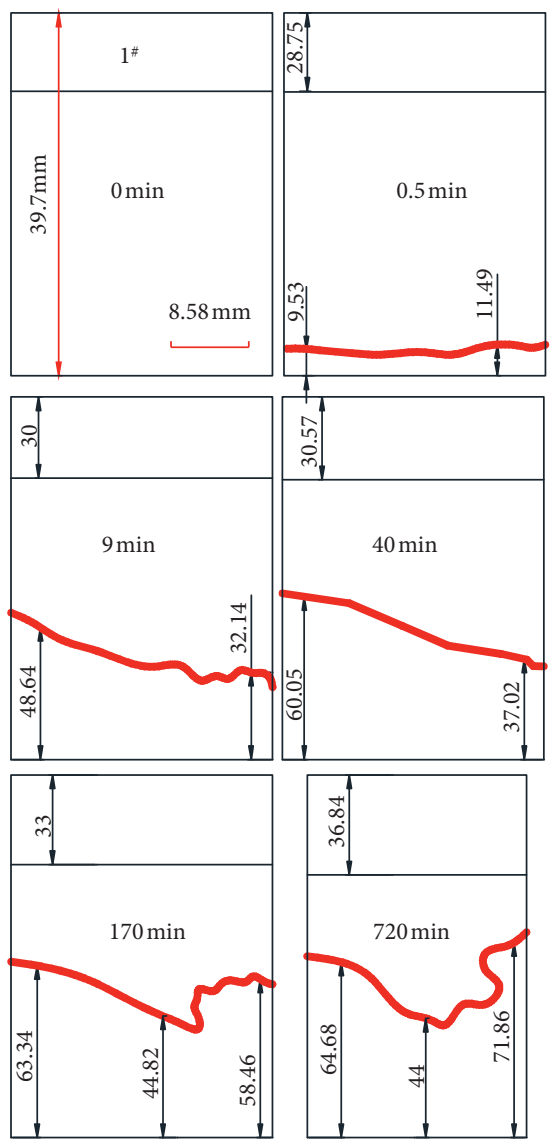

(a)
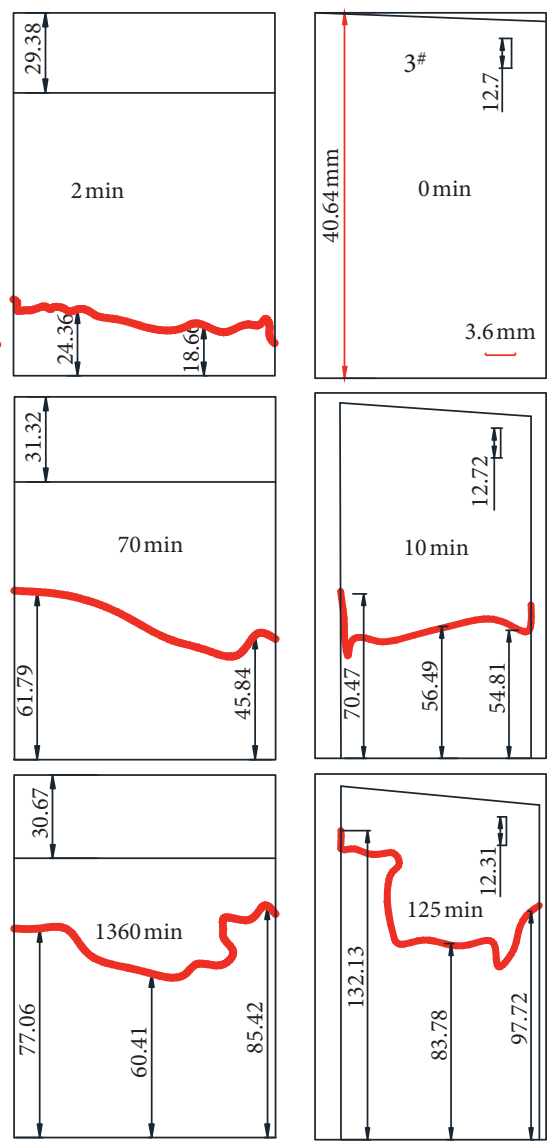
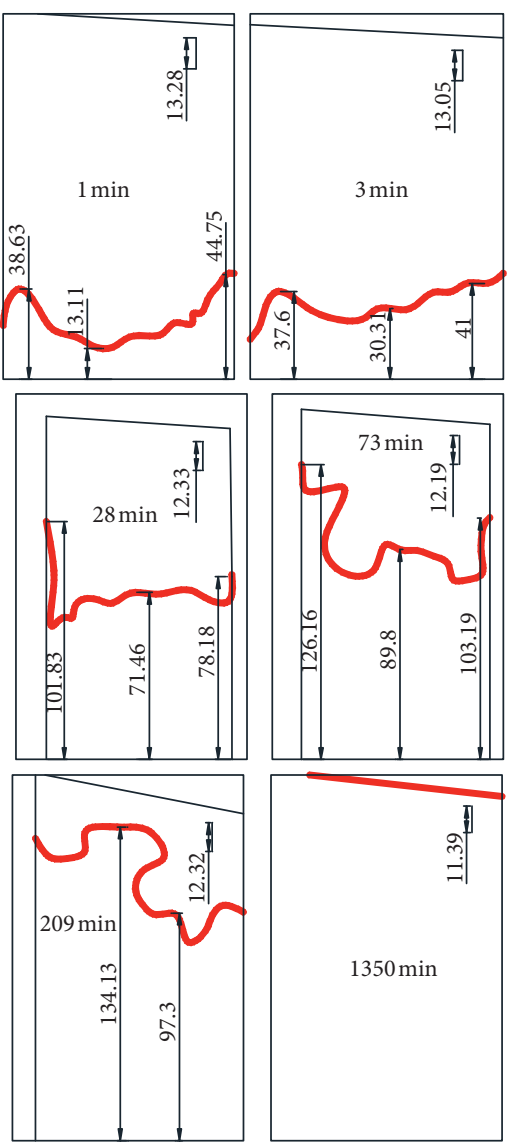

(b)

Figure 10: Variation of intruded line over time. (a) 1\# sample is under lateral restraints. (b) 3\# sample is under free restraints.

\section{Discussion}

When the weakly cemented silty mudstone is exposed to water, argillization and disintegration occur, leading to the loss of bearing capacity. So, water absorption has significant effects on the stability of surrounding rocks. The diffused distance and rate of water are determined by pore structures. Studying pore structures of weakly cemented mudstones is beneficial for understanding the water migration process.

4.1. Analysis of Pore Structures. Primary parameters of pores are listed in Table 5, which are measured by SEM, NAD, and MIP, respectively. Compared with shale, coarse sandstone, limestone, and rhyolites, the weakly cemented silty mudstone contains macropores, mesopores, and micropores $[38,39]$. The dispersion of each method is inevitable due to their distinct testing mechanisms [40, 41]. Large pores mainly concentrate in pore and fissure zones with the size of micronscale (see Figure 13). Skeleton aggregates appear to be compact. Pore scales of each zone are listed in Table 6. Figure 14 presents the mesostructure, including skeleton aggregates, pore, and fissure zones. Prior to porosity measurement, samples need to be broken into small fragments, $180 \sim 250 \mu \mathrm{m}$ in diameter for NAD, which approximates the size of the skeleton aggregates. It can be inferred that the PSD measured by NAD is mainly contributed by skeleton aggregates. The scale for MIP is larger than that for NAD, 


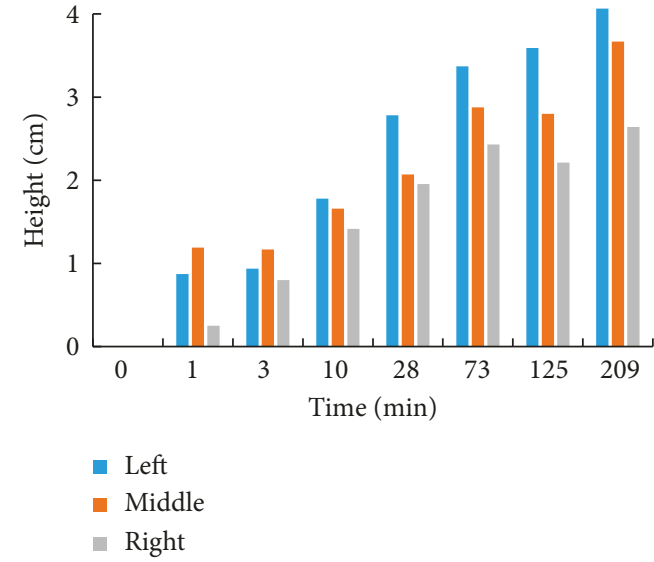

(a)

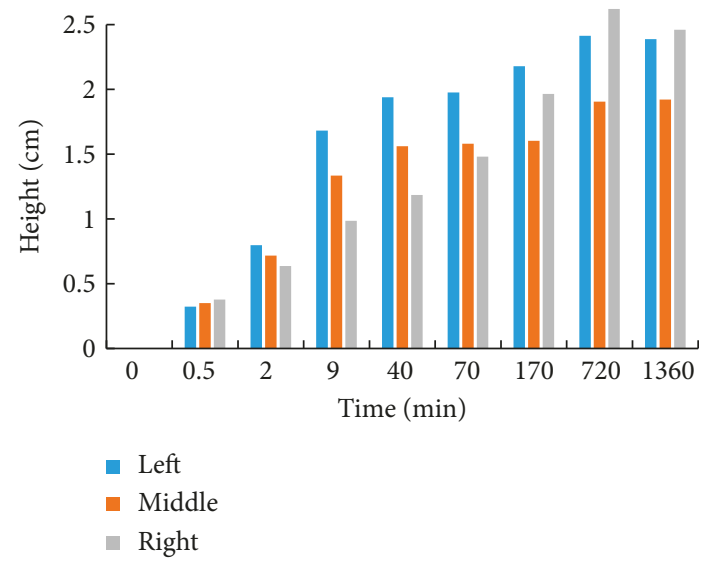

(b)

Figure 11: Height of intruded line over time. (a) 3\# sample is under free restraints. (b) 1\# sample is under lateral restraints.

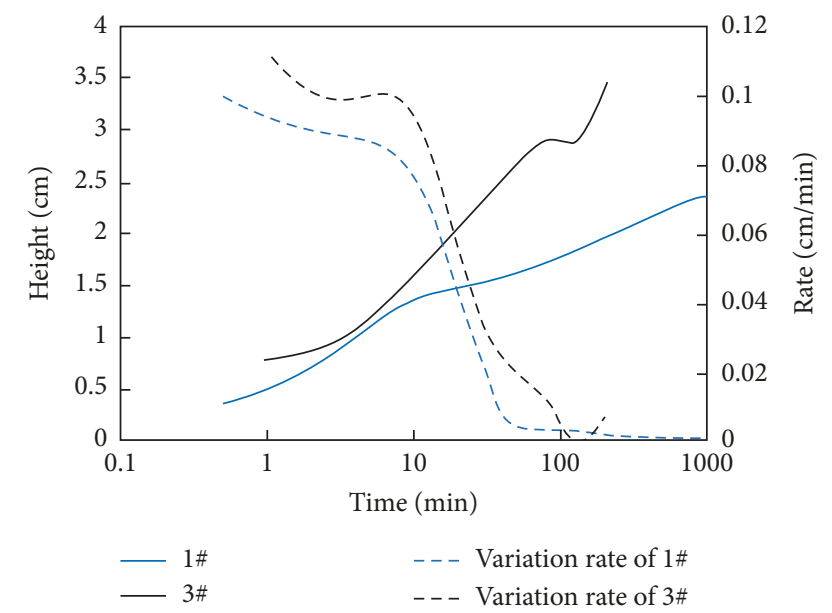

FIGURE 12: Variation rate of intruded height. 3\# sample is under free restraints. $1 \#$ sample is under lateral restraints.

TABle 5: Comparison of different test methods.

\begin{tabular}{|c|c|c|c|c|}
\hline $\begin{array}{l}\text { Test } \\
\text { method }\end{array}$ & $\mathrm{DM}$ & SEM & NAD & MIP \\
\hline $\begin{array}{l}\text { Average } \\
\text { PS }(\mu \mathrm{m})\end{array}$ & & 1.2000 & 0.0084 & 0.0140 \\
\hline $\operatorname{PSD}(\mu \mathrm{m})$ & & $0.2000 \sim 5.0000$ & $0.0030 \sim 0.2080$ & $0.0040 \sim 53.7330$ \\
\hline $\begin{array}{l}\text { Porosity } \\
(\%)\end{array}$ & 23.1 & & 13.5 & 20.8 \\
\hline
\end{tabular}

which includes skeleton aggregates and part pore zones, leading to larger porosity and pore sizes. The data measured by NAD and MIP are the porosity of connected pores. The total porosity is estimated as $23.1 \%$ by the density method (DM), which is larger than values of both MIP and NAD. Porosities of skeleton aggregates, pore, and fissure zones can be inferred approximately with the values of $13.5 \%, 7.3 \%$, and $2.3 \%$, respectively.

$\mathrm{DM}$ is an approximate porosity calculated by the equation $n=1-\rho_{d} /\left(G_{s} \cdot \rho_{w}\right)$, where $n$ is the total porosity;

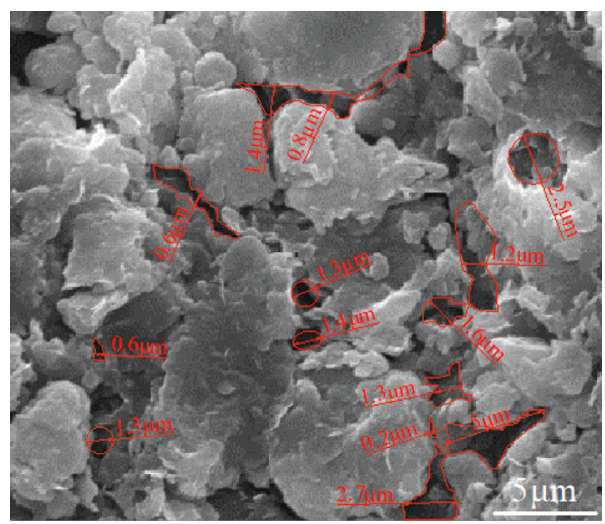

FIGURE 13: Pore characteristics measured by SEM.

TABle 6: Zone scales.

\begin{tabular}{lccc}
\hline Category & I & II & III \\
\hline Structure & Fissure zone & Pore zone & Skeleton aggregation \\
Scale & Micronscale & Submicronscale & Nanoscale \\
\hline
\end{tabular}

$\rho_{d}$ is the dry density, $1.97 \mathrm{~g} / \mathrm{cm}^{3} ; G_{s}$ is the specific gravity of granular mineral, 2.56; and $\rho_{w}$ is the water density, $1.00 \mathrm{~g} / \mathrm{cm}^{3}$.

4.2. Analysis on Water Migration. Water migration occurs when porous rocks are intruded by water. Mineral components and pore structure determine the moisture migration process. Meng et al. found that micron fissures extend at tips and openings increase simultaneously based on water absorption test on shale [42]. Distinguishing from adsorption process, intrusion occurs in larger pores first, and water intrudes into medium pores subsequently. Weakly cemented silty mudstone contains swelling clay minerals and larger porosity. The sample dilates when exposed to water, followed by swelling stress accumulation under lateral restraints. According to the diagram of water imbibition 


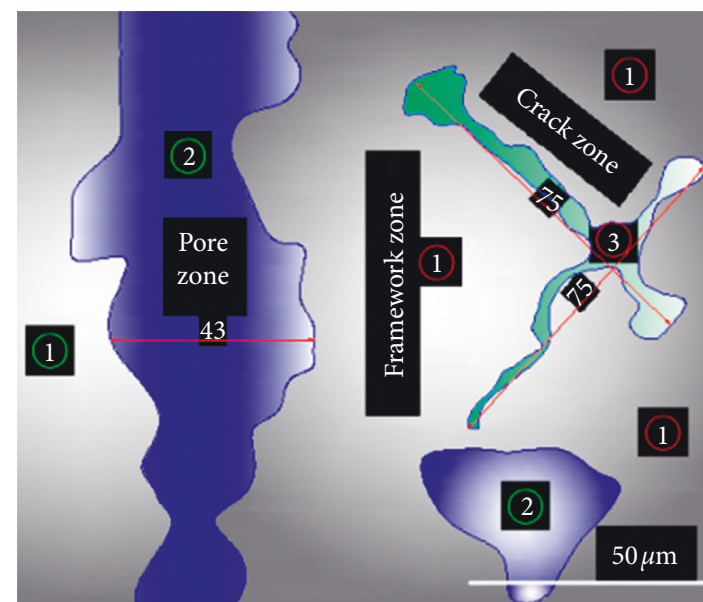

FIgURE 14: Microstructure of weakly cement mudstones.

over time, the water migration of weakly cemented silty mudstone is divided into three phases.

Firstly, water rises along fissure and pore zones under the capillary pressure. Intruded water will compress gas in voids, leading to the pore pressure increasing. On the one hand, the increased pore pressure acting on structures yields the tension at fissure tips, enlarging the opening and length of fissures; on the other hand, new micron fissures occur along the weakly connected band of large pores [43]. In turn, increased cracks promote the water movement. Water migration ends till the capillary force and the flow resistance are in balance. At last, fissure and pore zones are saturated with water. Secondly, clay and soluble minerals at edges of pore and fissure zones will dissolve after saturated with water, weakening the cementation between different structures. Illite and illite/smectite formation expand when exposed to water, forming new cracks along weak joints under the expansion force [44]. The added space provides new channels for water migration. Finally, nanoscale pores, which have a large specific surface energy and strong matrix suction in skeleton aggregates, can adsorb water from pore and fissure zones and achieve saturation gradually. Capillary resistance can prevent fluid from diffusing in pores less than $10 \mathrm{~nm}[45]$.

The surface of the swelling clay crystal which presents a negative charge adsorbs polarity water molecule under the electrostatic force. Thickness of the crystal layer can increase from $29 \AA$ to $33 \AA$, increasing the pore volume by $14 \%$ [46]. Weakly cemented mudstones contain swelling clay minerals of more than $15 \%$, and the high special surface energy leads to the strong binding capacity with moisture, forming hydration film coating particles and increasing the intercrystalline space. Pores will be compressed when lateral restraints are imposed, limiting water absorption and diffusion, corresponding to the 1\# sample (see Figure 9) [47].

4.3. Disintegration Characteristics. Weakly cemented silty mudstone disintegrates into small fragments, showing relative integrity when soaked in water (see Figure 15). However, the strength of fragments is too low. It is easy to

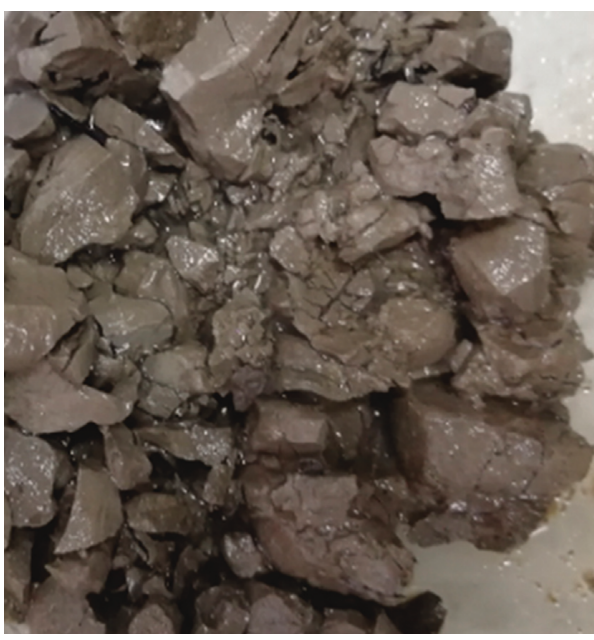

Figure 15: Disintegrated fragments.

split along the pore or fissure zone owing to the initial weak bonding. Skeleton aggregates, which seem to be compact with the pore size in nanoscale, absorb water from pore and fissure zones, containing clay-gel and solute carbonate as a role of cement $[48,49]$. Meanwhile, water existing in nanoscale pores cannot move or transfer hydrostatic pressure, which is distinct from free water. Interactions between water molecules and pore walls are strong for pores in nanoscale, yielding suction to maintain the integrity even under the saturation state.

\section{Conclusions}

Weakly cemented silty mudstone was characterized by weak cementation, high porosity, high water content, and swelling clay bearing. In this paper, pore properties of weakly cemented silty mudstone are measured by SEM, NAD, and MIP, respectively. In order to study the water migration process, a water absorption instrument is designed with special functions. Through water imbibition tests, the influence of pore structures on water migration is analyzed, and the main conclusions are summarized below:

(1) Weakly cemented silty mudstone contains three types of structures, including the fissure zone, pore zone, and skeleton aggregates. Cementation between structures is weak. Macropores present in fissure and pore zones, and mesopores and micropores present in skeleton aggregation zones. The porosities of each zone are inferred with the values of $13.5 \%, 7.3 \%$, and $2.3 \%$ by comparison of different methods.

(2) Three types of rock structures correspond to distinct channels of water absorption. Firstly, water migrates along large fissure and pore zones. Nanoscale pores in skeleton aggregates absorb water from pore and fissure zones gradually. The intruded line is uneven across the cross section due to anisotropy of pore structures. Channels of water migration extend and porosity increases resulting from the dilatation of clay minerals and gas compression. 
(3) Lateral restraints have an important effect on water migration. Exerting lateral restraints can limit the water imbibition. Water imbibition ends when capillary pressure is in balance with flow resistance or pores are saturated with water. Voids are compressed when lateral restraints are imposed, limiting water imbibition and migration. Weakly cemented silty mudstone disintegrates into small fragments, showing relative integrity when soaked in water.

This study had uncovered water imbibition mechanism for weakly cemented mudstone. However, water absorption will lead to changes of the pore structure, which changes the physical and mechanical properties of rocks. Therefore, it is of great significance to study the pore structure and effects on physical and mechanical properties after water imbibition.

\section{Data Availability}

The data used to support the findings of this study are available from the corresponding author upon request.

\section{Conflicts of Interest}

The authors declare that they have no conflicts of interest.

\section{Acknowledgments}

The first author is grateful to all the co-authors for providing innovative ideas, the State Key Laboratory for Geomechanics and Deep Underground Engineering, China University of Mining and Technology, for providing instruments to conduct the research, and Xiyi Coal Mine, subordinated by China Resources Power Holdings Company Limited, for providing geological data and rock cores. This study was supported by the National Natural Science Foundation of China (Nos. 51574223 and 51704280), Guizhou Science and Technology Support Plan Project (GZSCCB, No. [2018] 1061), and Guizhou Provincial Department of Education Youth Science and Technology Talent Growth Support Project (GZSCC No. [2017]219).

\section{Supplementary Materials}

The first one is a folder named "figure," which includes the original figures present in the manuscript. The second is also a folder named "NAD report." In the paper, the nitrogen adsorption desorption (NAD) tests of two sets of samples noted by CR-A and CR-B were carried out on Automatic Specific Surface Area and Pore Analyzer of TristarII3020 in the Key Lab of Coaled Methane Resources and Reservoir Formation Process, China University of Mining and Technology. There are two test reports in the folder. The third one is a PDF file named "EDITORIAL CERTIFICATE," indicating that the paper was edited for proper English language, grammar, punctuation, spelling, and overall style by one or more of the highly qualified native English speaking editors at ShiningStar Translation. The fourth one is a DOC file named "MIP report," including all the data of the MIP test. The MIP test was conducted on 9505 Auto Pore IV Mercury Porosimeters in Beijing, which can identify pore size ranging from $0.003 \mu \mathrm{m}$ to $1100 \mu \mathrm{m}$. The last one was a excel file named "water absorption and MIP results," including the data of water absorption tests. (Supplementary Materials)

\section{References}

[1] S. Tang, "The effects of water on the strength of black sandstone in a brittle regime," Engineering Geology, vol. 239, pp. 167-178, 2018.

[2] A. M. Robertson, "Lateral swelling pressures in active clay," in Proceedings of the 6th Regional Conference for Africa on Soil Mechanics and Foundation Engineering, Durban, South Africa, 1975.

[3] W. B. Lindquist, A. Venkatarangan, J. Dunsmuir, and T.-f. Wong, "Pore and throat size distributions measured from synchrotron X-ray tomographic images of Fontainebleau sandstones," Journal of Geophysical Research: Solid Earth, vol. 105, no. B9, pp. 21509-21527, 2000.

[4] Y. Ji, P. Baud, V. Vajdova, and T.-f. Wong, "Characterization of pore geometry of Indiana limestone in relation to mechanical compaction," Oil \& Gas Science and TechnologyRevue d'IFP Energies nouvelles, vol. 67, no. 5, pp. 753-775, 2012.

[5] W. Liu, Y. Li, C. Yang, J. J. K. Daemen, Y. Yang, and G. Zhang, "Permeability characteristics of mudstone cap rock and interlayers in bedded salt formations and tightness assessment for underground gas storage caverns," Engineering Geology, vol. 193, pp. 212-223, 2015.

[6] N. Zhang, M. He, and P. Liu, "Water vapor sorption and its mechanical effect on clay-bearing conglomerate selected from China," Engineering Geology, vol. 141-142, pp. 1-8, 2012.

[7] H. Guo, M. He, C. Sun, B. Li, and F. Zhang, "Hydrophilic and strength-softening characteristics of calcareous shale in deep mines," Journal of Rock Mechanics and Geotechnical Engineering, vol. 4, no. 4, pp. 344-351, 2012.

[8] E. Yilmaz, Investigating the hydrogeotechnical and microstructural properties of cemented paste backfills using the versatile CUAPS apparatus, Ph.D. Thesis, Université du Québec en Abitibi-Témiscamingue (UQAT), Rouyn-Noranda, QC, Canada, 2010.

[9] E. Yilmaz, T. Belem, B. Bussière, and M. Benzaazoua, "Relationships between microstructural properties and compressive strength of consolidated and unconsolidated cemented paste backfills," Cement and Concrete Composites, vol. 33, no. 6, pp. 702-715, 2011.

[10] S. Cao, E. Yilmaz, and W. Song, "Evaluation of viscosity, strength and microstructural properties of cemented tailings backfill," Minerals, vol. 8, no. 8, p. 352, 2018.

[11] S. Raynaud, D. Fabre, F. Mazerolle et al., "Analysis of the internal structure of rocks and characterization of mechanical deformation by a non-destructive method: X-ray tomodensitometry," Tectonophysics, vol. 159, pp. 49-59, 1989.

[12] C. Janssen, R. Wirth, A. Reinicke et al., "Nanoscale porosity in SAFOD core samples (san andreas fault)," Earth and Planetary Science Letters, vol. 301, no. 1-2, pp. 179-189, 2011.

[13] Z. Li, X. Shen, Z. Qi, and R. Hu, "Study on the pore structure and fractal characteristics of marine and continental shale based on mercury porosimetry, $\mathrm{N}_{2}$ adsorption and NMR methods," Journal of Natural Gas Science and Engineering, vol. 53, pp. 12-21, 2018. 
[14] E. C. Gaucher, P. D. C. Défossez, D. Bonijoly et al., "Coal laboratory characterisation for $\mathrm{CO}_{2}$ geological storage," Energy Procedia, vol. 4, pp. 3147-3154, 2011.

[15] J. Hadizadeh, R. Sehhati, and T. Tullis, "Porosity and particle shape changes leading to shear localization in smalldisplacement faults," Journal of Structural Geology, vol. 32, no. 11, pp. 1712-1720, 2010.

[16] J. D. Frost and D.-J. Jang, "Evolution of sand microstructure during shear," Journal of Geotechnical and Geoenvironmental Engineering, vol. 126, no. 2, pp. 116-130, 2000.

[17] S. Saraji and M. Piri, "The representative sample size in shale oil rocks and nano-scale characterization of transport properties," International Journal of Coal Geology, vol. 146, pp. 42-54, 2015.

[18] M. S. Allen, E. E. Christopher, and C. H. Erin, "Porosity and pore size distribution in a sedimentary rock: implications for the distribution of chlorinated solvents," Journal of Contaminant Hydrology, vol. 203, pp. 70-84, 2017.

[19] M. Á. García-del-Cura, D. Benavente, J. Martínez-Martínez, and N. Cueto, "Sedimentary structures and physical properties of travertine and carbonate tufa building stone," Construction and Building Materials, vol. 28, no. 1, pp. 456467, 2012.

[20] S. Galvañ, C. Pla, N. Cueto et al., "A comparison of experimental methods for measuring water permeability of porous building rocks," Materiales de Construcción, vol. 64, no. 315, pp. 1-10, 2014.

[21] B. B. Hodot, Outburst of Coal and Coalbed Gas (Chinese Translation), p. 318, China Industry Press, Beijing, China, 1966.

[22] K. S. W. Sing, "Reporting physisorption data for gas/solid systems with special reference to the determination of surface area and porosity (recommendations 1984)," Pure \& Applied Chemistry, vol. 57, no. 11, pp. 603-619, 1985.

[23] F. A. L. Dullien, Porous Media Fluid Transport and Pore Structure, Academic Press, San Diego, CA, USA, 1992.

[24] J. H. Schön, "Physical properties of rocks: fundamentals and principles of petrophysics," in Handbook of Geophysical Exploration, Elsevier, Oxford, UK, 2011.

[25] T. Lerouge, O. Pitois, D. Grande, B. Le Droumaguet, and P. Coussot, "Synergistic actions of mixed small and large pores for capillary absorption through biporous polymeric materials," Soft Matter, vol. 14, no. 40, pp. 8137-8146, 2018.

[26] T. R. Harper, G. Appel, M. W. Pendleton, J. S. Szymanski, and R. K. Taylor, "Swelling strain development in sedimentary rock in Northern New York," International Journal of Rock Mechanics and Mining Sciences \& Geomechanics Abstracts, vol. 16, no. 5, pp. 271-292, 1979.

[27] E. Ghanbari and H. Dehghanpour, "Impact of rock fabric on water imbibition and salt diffusion in gas shales," International Journal of Coal Geology, vol. 138, pp. 55-67, 2015.

[28] Y. Huang, Q. Chen, and R. Wang, "Visualization study on capillary-spreading behavior of liquid droplet in vertically aligned carbon nanotube array," International Journal of Heat and Mass Transfer, vol. 120, pp. 1055-1064, 2018.

[29] L. Yang, N. Dou, X. Lu et al., "Advances in understanding imbibition characteristics of shale using an NMR technique: a comparative study of marine and continental shale," Journal of Geophysics and Engineering, vol. 15, no. 4, pp. 1363-1375, 2018.

[30] L. Yang, H. Ge, X. Shi et al., "The effect of microstructure and rock mineralogy on water imbibition characteristics in tight reservoirs," Journal of Natural Gas Science and Engineering, vol. 34, pp. 1461-1471, 2016.
[31] J. Shen, J. Zhao, Y. Qin, Y. Shen, and G. Wang, "Water imbibition and drainage of high rank coals in Qinshui Basin, China," Fuel, vol. 211, pp. 48-59, 2018.

[32] F. Lai, Z. Li, T. Zhang, A. Zhou, and B. Gong, "Characteristics of microscopic pore structure and its influence on spontaneous imbibition of tight gas reservoir in the Ordos Basin, China," Journal of Petroleum Science and Engineering, vol. 172, pp. 23-31, 2019.

[33] E. W. Washburn, "The dynamics of capillary flow," Physical Review, vol. 17, no. 3, pp. 273-283, 1921.

[34] E. W. Washburn, "Note on a method of determining the distribution of pore sizes in a porous material," Proceedings of the National Academy of Sciences, vol. 7, no. 4, pp. 115-116, 1921.

[35] K. Makhanov, H. Dehghanpour, and E. Kuru, "An experimental study of spontaneous imbibition in Horn River shales," in Proceedings of the SPE Canadian Unconventional Resources Conference, Calgary, Alberta, Canada, 2012.

[36] E. P. Barrett, L. G. Joyner, and P. P. Halenda, "The determination of pore volume and area distributions in porous substances. I. Computations from nitrogen isotherms," Journal of the American Chemical Society, vol. 73, no. 1, pp. 373-380, 1951.

[37] M. Thommes, K. Kaneko, A. V. Neimark et al., "Physisorption of gases, with special reference to the evaluation of surface area and pore size distribution (IUPAC technical report)," Pure \& Applied Chemistry, vol. 87, no. 9-10, pp. 1051-1069, 2015.

[38] J. T. Fredrich, B. Menendez, and T.-F. Wong, "Imaging the pore structure of geomaterials," Science, vol. 268, no. 5208, pp. 276-279, 1995.

[39] M. Milner, R. McLin, and J. Petriello, "Imaging texture and porosity in mudstones and shales: comparison of secondary and ion-milled backscatter SEM methods, CSUG/SPE 138975," in Proceedings of the Canadian Unconventional Resources and International Petroleum Conference, Calgary, Alberta, Canada, 2010.

[40] C. R. Clarkson, N. Solano, R. M. Bustin et al., "Pore structure characterization of North American shale gas reservoirs using USANS/SANS, gas adsorption, and mercury intrusion," Fuel, vol. 103, pp. 606-616, 2013.

[41] A. A. Hinai, R. Rezaee, L. Esteban, and M. Labani, "Comparisons of pore size distribution: a case from the Western Australian gas shale formations," Journal of Unconventional Oil and Gas Resources, vol. 8, pp. 1-13, 2014.

[42] M. Meng, H. Ge, W. Ji, and X. Wang, "Research on the autoremoval mechanism of shale aqueous phase trapping using low field nuclear magnetic resonance technique," Journal of Petroleum Science and Engineering, vol. 137, pp. 63-73, 2016.

[43] K. Terzaghi and R. B. Peck, Soil Mechanics in Engineering Practice, John Wiley \& Sons, New York, NY, USA, 1967.

[44] I. J. A. Brackley, "A model of unsaturated clay structure and its application to swell behavior," in Proceedings of the 6th Regional Conference for Africa on Soil Mechanics and Foundation Engineering, pp. 71-79, Darban, South Africa, 1975.

[45] P. Marschall, S. Horseman, and T. Gimmi, "Characterisation of gas transport properties of the opalinus clay, a potential host rock formation for radioactive waste disposal," Oil \& Gas Science and Technology, vol. 60, no. 1, pp. 121-139, 2005.

[46] W. Wittke and B. Pierau, "Foundation for design and construction of tunnel in swelling rock," in Proceeding of the 4th International Congress on Rock Mechanics, pp. 219-729, Montreux, Switerland, 1979. 
[47] D. S. Cui, W. Xiang, and L. J. Cao, "Experimental study on reducing thickness of absorbed water layer for red clay particles treated by ionic soil stabilizer," Chinese Journal of Geotechnical Engineering, vol. 32, no. 6, pp. 944-949, 2010.

[48] A. E. Milodowski, M. R. Cave, S. J. Kemp et al., "Mineralogical investigations of the interaction between iron corrosion products and bentonite from the NF-PRO experiments (phase 2)," British Geological Survey Commissioned Report, p. 76, 2007.

[49] D. Svensson, A. Dueck, U. Nilsson et al., "Alternative buffer material, status of the ongoing laboratory investigation of reference materials and test package 1," Technical Report, TR11-06, Swedish Nuclear Fuel and Waste Management Co., Sweden, 2011. 


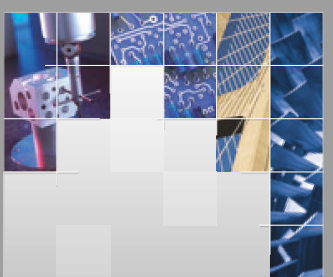

\section{Enfincering}
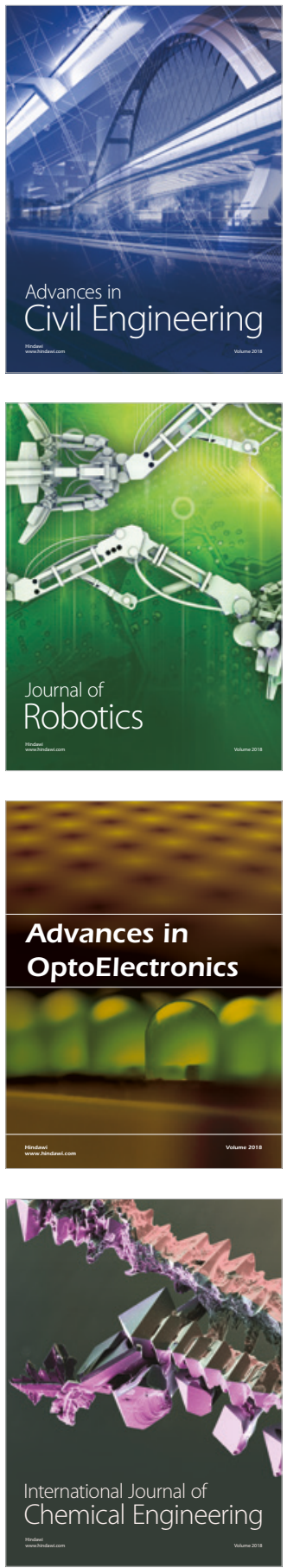

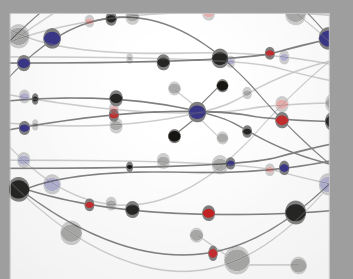

\section{Rotating \\ Machinery}

The Scientific World Journal

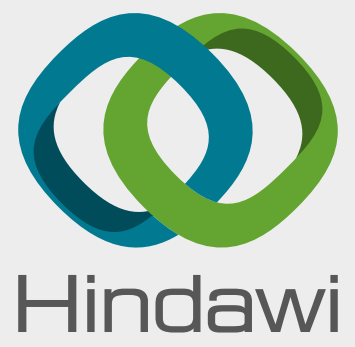

Submit your manuscripts at

www.hindawi.com
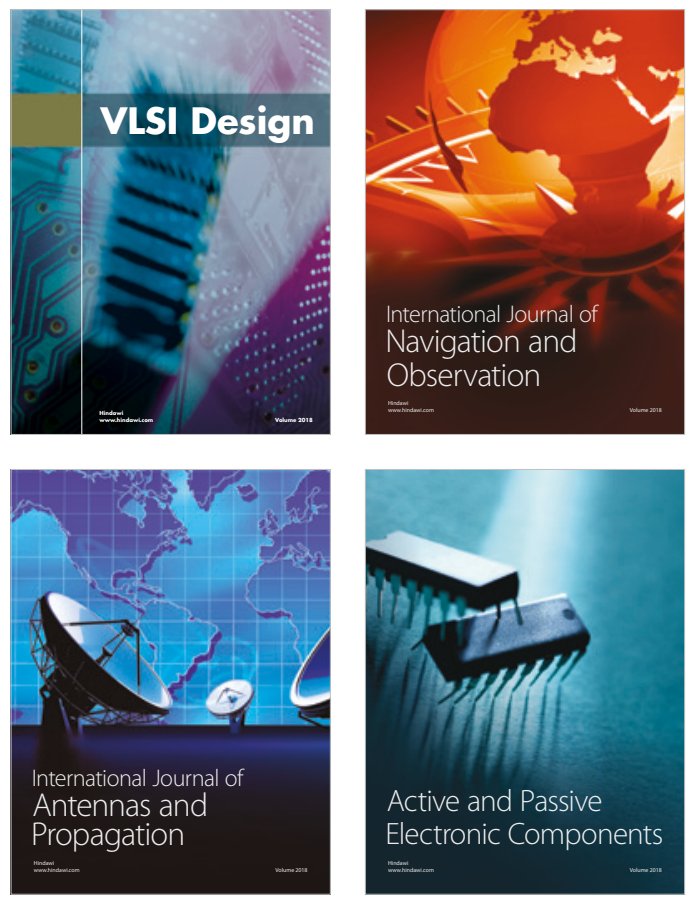
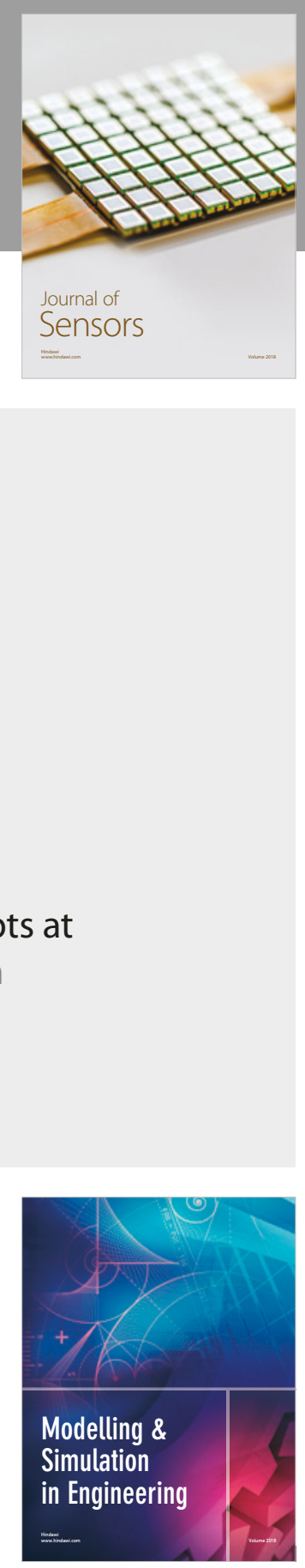

\section{Advances \\ Multimedia}
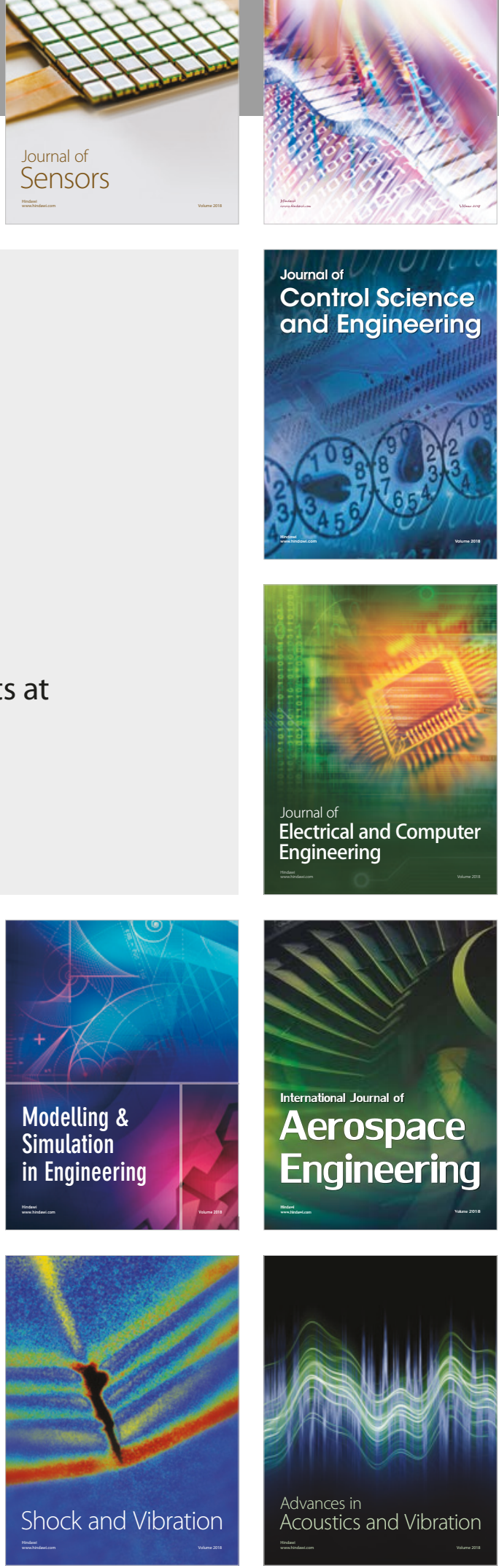